\title{
Vulnerability index and climate change: An analysis in Cuddalore District of Tamil Nadu, India
}

\author{
R. GEETHA ${ }^{1}$, SHOBA JOE KIZHAKUDAN ${ }^{1}$, INDIRA DIVIPALA², SHYAM S. SALIM ${ }^{3}$ \\ AND P. U. ZACHARIA ${ }^{3}$ \\ ${ }^{1}$ Madras Research Centre of ICAR-Central Marine Fisheries Research Institute, Chennai - 600 028, Tamil Nadu, India \\ ${ }^{2}$ Visakhapatnam Regional Centre of ICAR-Central Marine Fisheries Research Institute, Visakhapatnam - 530003 \\ Andhra Pradesh, India \\ ${ }^{3}$ ICAR-Central Marine Fisheries Research Institute, Kochi - 682 018, Kerala, India \\ e-mail: geethaeconomist@rediffmail.com
}

\begin{abstract}
Erratic monsoon and extreme climatic events cause considerable damage to life and property of the fishers in the country. Cuddalore District has been the worst affected of all districts in Tamil Nadu, in the recent past with the tsunami in 2004, cyclone Thane in 2011 and cyclone Neelam in 2012 creating a detrimental impact on coastal communities and their activities, particularly fishing. This in turn has affected their livelihood to a great extent. This coastal zone is largely low-lying with gentle slope, thus making it highly vulnerable to climate related changes. The vulnerability of this region to climate change and its devastating effects necessitates identifying vulnerability indices to assist in developing proactive policies by local government bodies in better disaster management. The vulnerability index of ten coastal villages of Cuddalore District was computed using Parameter, Attribute, Resilient indicator and Score (PARS) method. The study showed that the Cuddalore coast is highly vulnerable to climate change and related sea level rise. The villages of Pettodai, Reddiarpettai and Sothikuppam of Cuddalore District were identified as most vulnerable. The outcome of this study will be of use in the protection of coastal livelihoods and planning better adaptation policies and mitigation plans.
\end{abstract}

Keywords: Attributes, Climate change, Fisher's perception, Parameters, Vulnerability indices

\section{Introduction}

Coastal environments are under increasing pressure from both rapid anthropogenic development and predicted consequences of climate change, such as sea level rise, coastal erosion and extreme weather events. About 23\% of the world's population live within $100 \mathrm{~km}$ of the coast and about $10 \%$ live in extremely low-lying areas $(<10 \mathrm{~m}$ above mean sea level) (Small and Nicholls, 2003). Many geophysical processes like coastal erosion, storm surges, coastal flooding, tsunamis and rise in sea level pose hazards to these people. The intensity of each of these processes is likely to increase under changing scenarios of global climate. Vulnerability is a function of the character, magnitude and rate of climate change and variation to which a system is exposed, its sensitivity, and its adaptive capacity. IPCC (2007) defines vulnerability as "the degree to which a system is susceptible to and unable to cope with, adverse effects of climate change, including climate variability and extremes. Vulnerability is conceptualised in different ways across different disciplines due to the fact that the term "vulnerability" has been used in different policy contexts, referring to different systems exposed to different hazards. Susceptibility of natural or social systems to sustain damage from climate change and the ability or lack of the exposure unit to cope, recover or fundamentally adapt to become a new system or to become extinct, have all been linked to definitions of vulnerability (Kasperson et al., 2003).

With a long coast line of about 7,500 km and several low-lying coastal areas, India is particularly vulnerable to coastal erosion and flooding and is one among the 27 countries in the world identified as most vulnerable to sea level rise by the United Nations Environment Programme. More than three hundred million people or nearly $26 \%$ of the total population, live in the coastal zone of India. Continuing dependence upon fisheries for food and livelihood makes the people vulnerable to climate variation and change. The Bay of Bengal is one of the six regions in the world where severe tropical cyclones originate and this area in particular was one of the worst hit during 2004 Indian Ocean tsunami. It experiences severe tropical cyclones during north-east monsoon (October through December) and from 1737 to 2015 , there have been 23 major surge events in 
the Bay of Bengal, accounting for 10,000 human lives lost during each event (Murthy et al., 2006). An analysis of the annual cyclones and severe cyclonic storms in the Bay of Bengal region clearly indicates that although the frequency of cyclones has decreased after 1980, there has been a marginal increase in the occurrence of severe cyclonic storms, which in turn implies an increase in storm magnitude (Dube et al., 1997). The Indian east coast is more vulnerable than the west coast with respect to the frequency of occurrence of extreme events like cyclones and depressions (Patwardhan et al., 2003).

Vulnerability to climatic change is a multi-dimensional process and generally coastal districts are more vulnerable to climatic change. Hence it is necessary to assess the quantum of vulnerability by constructing a vulnerability index for each village. Several vulnerability studies have been undertaken along the east coast as well as west coast for sea-level rise using physical variables as an input to the coastal vulnerability index. Shoreline movement (Mani Murali et al., 2009) and run up as well as inundation limits (Jayakumar et al., 2005) were studied along the parts of east coast of India for anthropogenic and tsunami impact studies respectively. Ramanamurthy et al. (2005) observed that the worst affected Nagapattinam area in the southern state of Tamil Nadu along the east coast of India had longer penetration of tsunami inland due to gentle slope of the coastal land. Dwarakish et al. (2009) calculated the Coastal Vulnerability Index (CVI) for the coastal zone of Udupi, Karnataka from 15 shoreline change parameters which includes, rate of sea-level change, coastal slope, tidal range and coastal geomorphology. CVI for Odisha was assessed by Kumar et al. (2010) using an additional parameter of tsunami run-up. The multi-hazard vulnerability along the coast of Cuddalore-Villupuram was assessed by Mahendra et al. (2011) by incorporating storm surge parameter along with other physical factors. Kumar et al. (2012) did a vulnerability assessment of Chennai coast using geo-spatial technologies.

Along the east coast, Cuddalore District in Tamil Nadu is particularly prone to storms, super storms and depressions. Notably, the inhabitants of these villages are mainly hut-dwelling fishing communities who are highly vulnerable in socio-economic terms as well. Hence this study was conducted to identify the vulnerability indices of coastal villages in Cuddalore due to impact of the warming climate which will be a key step towards effective planning and implementation of disaster management and mitigation measures.

\section{Materials and methods}

\section{Selection of study area}

The selected study area is the region along Cuddalore coast in the state of Tamil Nadu situated on the east coast of
India, between $11^{\circ} 44^{\prime} 45^{\prime \prime} \mathrm{N}$ and $79^{\circ} 45^{\prime} 56^{\prime} \mathrm{E}$. The coastal stretch of Cuddalore extends from Gadilam Estuary in the north to Pichavaram mangroves in the south, a total length of $42 \mathrm{~km}$ along the Bay of Bengal. (Saxena et al., 2012). Cuddalore comprises two taluks namely Chidambaram and Cuddalore with 42 coastal fishing villages. Cuddalore region of South India is a low lying coastal zone that suffered significant erosion in recent years. It has been severely affected by the tsunami of 2004, floods and cyclones. Subsequently, Cyclone Nisha in 2008 and Cyclone Thane in December 2011 created surge heights between 1 and $1.5 \mathrm{~m}$ at Cuddalore District. Cyclone Thane resulted in extensive damage of life and property. There are 12,975 fishers living in 14 settlements of 10 coastal villages of Cuddalore District within the hazard line (CMFRI, 2006). The present research study was conducted to examine vulnerability of households across the coastal districts by developing vulnerability indices comprising of various parameters, attributes and indicators, for the selected villages of Cuddalore District which will provide policy inputs in developing climate change adaptation measures which can be used for the policy measures by concerned Government.

The selection of coastal villages of Cuddalore District for the study was based on the impact of earlier cyclones and other climatic events as well as on certain parameters viz., socio-economic factors, average family size, number of families below poverty line, literacy rate, dependence on fishing activities, craft and gear combinations, participation in cooperatives and other allied activities. The study was conducted for a period of 9 months from April to December 2013.

\section{Vulnerability assessment}

The vulnerability of fisherfolk towards climate change was assessed through indices by employing Parameter, Attribute and Resilient indicator and Score (PARS) methodology. This is a conceptual framework developed for assessing the climate change vulnerability of coastal livelihoods (Shyam et al., 2014). A list of possible attributes in each groups and their relationship are shown in Fig. 1.

The possible sources of vulnerability were identified and for each source, several parameters and attributes were also identified. The variables were grouped into five sources, namely, environment, fishery, social, economic and development drivers. The parameters and attributes were selected based on the information obtained from primary and secondary sources. For each parameter, a number of relevant attributes were developed. In this context, a group of ten villages viz., Thazhanguda, 


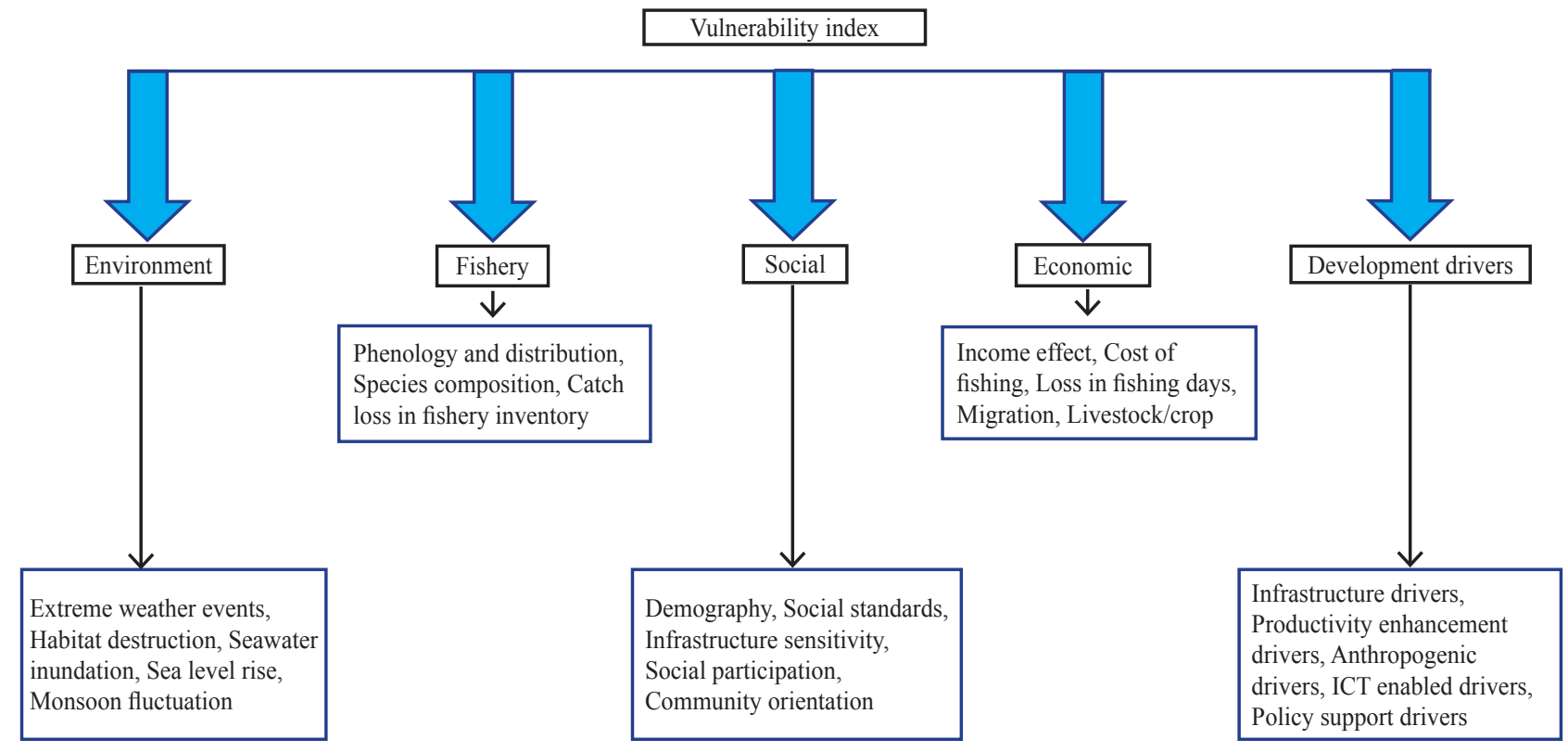

Fig 1. PARS methodology framework (Shyam et al., 2014)

Sonankuppam, Sothikuppam, Rasapettai, Chithiraipettai, Thammanampettai, Pettodai, Reddiarpettai, Samiyarpettai and Chinnur Pudupettai were selected and 100 households from each village were randomly chosen and interviewed.

From Cuddalore coastal villages, the samples were drawn based on the distribution of households along the coastline. A well-structured schedule was administered eliciting information on the education, savings, assets, awareness on climate change and perception on the climate change causal factors of the fisher households. The level of awareness preparedness and mitigation, alternate avocation options, community involvement and mobilisation and the level of governmental support and requirements were also collected.

The schedules were constructed based on the indicators, parameters and attributes (Fig. 1). PARS methodology provides prioritisation and ranking of different impacts as perceived by the fishers and the framework allows adequate distribution between fishing. The fishers were asked to rank from 1 - 5 indicating the severity of the vulnerability: 5 indicates very high, 4 - high, 3 - medium, 2 - low and 1- negligible/marginal. Each parameter will lead to different attributes and the attributes will lead to different statements or resilient indicators which will be based on different scores.

The vulnerability indices were then worked out for each parameter and attributes. Secondary data were also used to cross check the fisher folk's response and results obtained by this analysis. The values were worked out for each attributes and the analysis was done based on 119 attributes in the schedule, which are related to climate change.

The rank based quotient technique was used to analyse the scores and the ranks were made in such a way that the most affected attribute will get the highest ranking. PARS methodology was analysed using rank based quotient (RBQ) formula of Sabarathnam (1988):

Rank based quotient $=\sum_{\mathrm{i}-1}^{\mathrm{n}}(\mathrm{Fi})(\mathrm{n}+1-\mathrm{i}) \times \frac{100}{\mathrm{Nn}}$

where, $F_{i}=$ number of farmers reporting a particular problem under $i^{\text {th }}$ rank, $n=$ number of problems identified and $\mathrm{N}=$ number of fishers. Vulnerability indices were worked out for each component and made amenable for comparison to assess differences in vulnerabilities between different villages (Bhattacharya and Das, 2007).

\section{Results and discussion}

Vulnerability by climate related changes were grouped into five components namely, environment, fishery, social, economic and development drivers. The methodology adopted was useful in identifying the most relevant criteria significant to climate change vulnerability factors viz., parameters and attributes. This would help the climatologists and policy makers to implement climate adaptation and mitigation plans for the concerned villages, districts and states. This methodology was applied in an effort to understand the attributes of coastal vulnerability in the selected fishing villages of Cuddalore District, in 
order to scale up the impacts, adaptations and mitigation plans of coastal livelihoods to the district level. It helped to assess the impact of climate change on the five different indicators considered.

\section{Fishers 'perception on climate attributes}

Composite vulnerability index of Cuddalore District was 55.6 which was arrived based on 5 indicators and 119 attributes. The data on the composite villages for Cuddalore District indicated that fishery is the most impacted parameter as a result of climate change followed by development drivers and social factors. The results indicated that the direct impact of climate change on fisheries ecosystems affected coast of Cuddalore and the parameter "fisheries" was impacted more than other parameters (Fig. 2). In addition, the village vulnerability index map prepared for Cuddalore based on the index values suggested highest impact on fisheries compared to other parameters. (Fig. 3).

It was found that the most vulnerable areas to climatic changes perform very low in terms of infrastructure. Therefore the presence of infrastructure services in a particular region seriously affects the vulnerability condition of that area. Due to the unusual climatic behaviour in recent years, people in these villages face serious vulnerability issues, especially in the context of human settlements and consequently move out to other places to combat the situation (Ahamed, 2013). A low level of development in these areas is a greater problem and has a direct impact on the prospects of current and future vulnerability of the people living in these areas (Patnaik and Narayan, 2005). This increases the scale of vulnerability because a larger proportion of the population is exposed to extreme events. Environmental parameter is the least impacted as perceived by the fishers.

\section{Parameter and attribute analysis of coastal villages}

a) Attribute analysis of climate change impacts on fishery

The results of the study indicated that the fishery was impacted mostly by phenology and distribution.

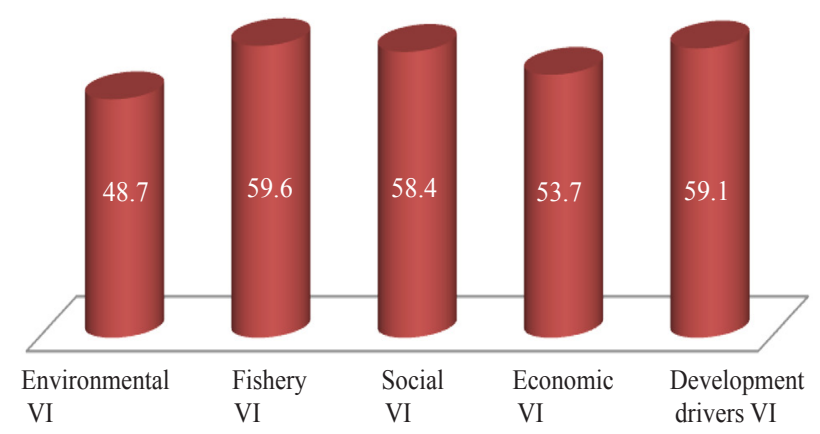

Fig. 2. Vulnerability indices with respect to different indicators for Cuddalore District; VI: Vulnerability index

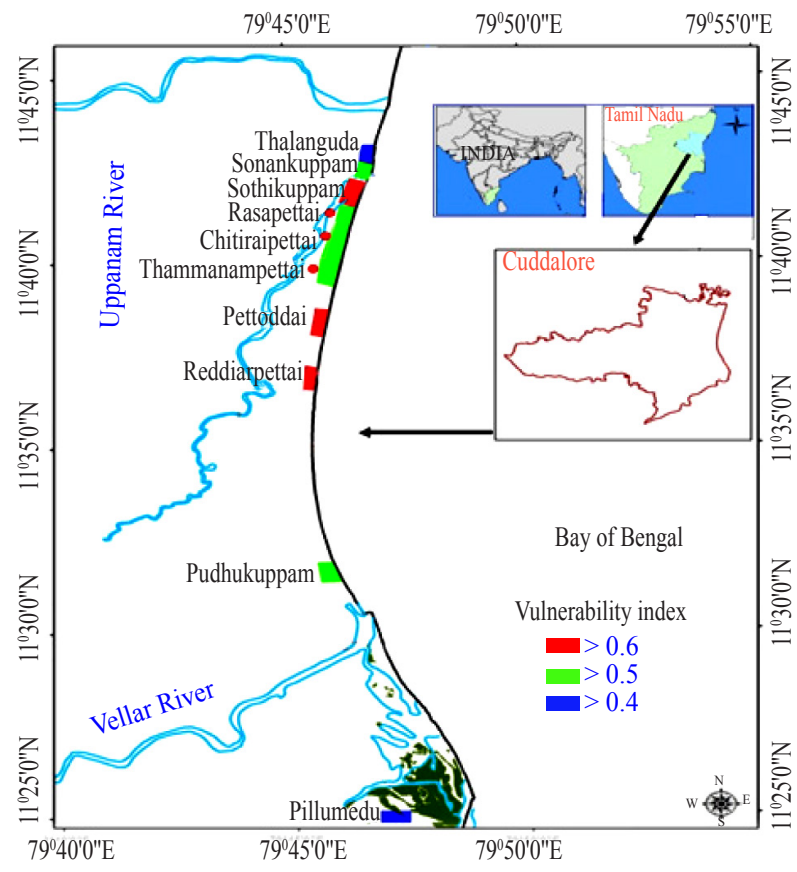

Fig. 3. Vulnerability indices (VI) for ten fishing villages of Cuddalore District, Tamil Nadu

Fishers perceived that distribution, species composition and catch have been drastically changed over the years in the coastal areas of Cuddalore (Fig. 4 ) and ranked the above mentioned fishery attribute as high which caused increased vulnerability. Vivekanandan (2006) reported that the effects of climate change on fisheries will affect the fisheries sector that is already characterised by stagnating catches, full utilisation of resources, large overcapacity and conflicts among fishers. Allison et al. (2009) suggested that climate change impacts are likely to lead to either increased economic hardship or missed opportunities for development in countries that depend on fisheries, but lack the capacity to adapt. As per the opinion of fishers in Kerala, shift in spawning season, migration of coastal fishes to open sea and pelagic fishes to deeper waters have taken place along the coast due to climate change which has resulted in drastic reduction of fish catch over the years while effort has increased to a higher level (Shyam et al., 2014).

\section{b) Attributes analysis of climate change impacts on development drivers}

Fishers perceived that development drivers were impacted next to fishery in the context of climate change. Fishers opined infrastructure drivers as highly vulnerable attribute of development drivers which raised climatic impact in Cuddalore District of Tamil Nadu followed by policy support drivers and ICT enabled drivers. The anthropogenic and productivity enhancement drivers were 


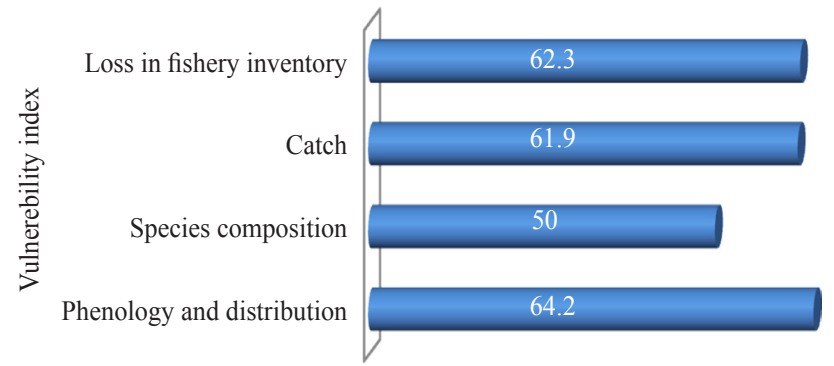

Fig. 4. Attribute analysis on fishery vulnerability; VI: Vulnerability index

least impacted. It showed that unregulated development of industries and related infrastructure and transportation facilities have increased in recent years in Cuddalore which led to enhancement of vulnerability to climate change impacts (Fig. 5). Fishers perceive that inadequate saving cum relief measures and unplanned rehabilitation measures made this district more vulnerable.

\section{c) Attributes analysis of climate change impacts on social aspects}

According to fishers' perception, social attributes were third most impacted. The attribute on infrastructure sensitivity ranked highest, followed by social participation and demography while social standards were least impacted. The infrastructure facilities are very low (Patnaik and Narayan, 2005) and most of the villages in Cuddalore

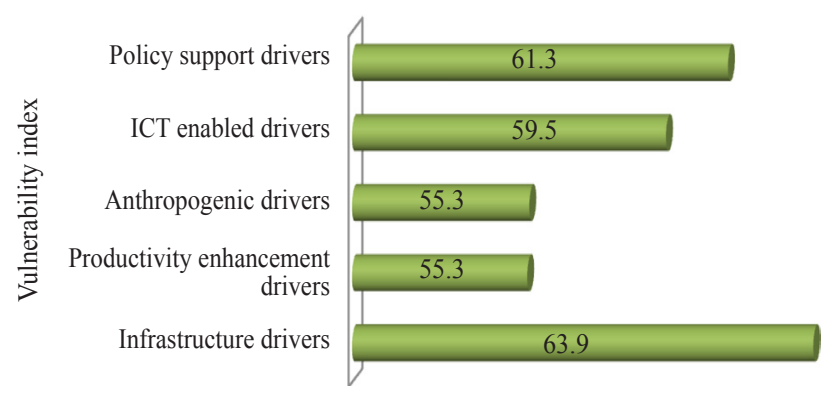

Fig. 5. Attribute analysis on development drivers vulnerability; VI: Vulnerability index

are situated on hazard zone. Maximum extent of the hazard zone is seen as $20 \mathrm{~km}$ from the current coastline of the Cuddalore District (Mahendra et al., 2011). In terms of demography, human settlements and the people living in the area are also directly affected by the negative shocks like cyclones, floods, droughts and sea level rise. Also the damages to physical infrastructure will be more in these villages due to the high vulnerability (Fig. 6). Factors like institutional stability and strength of public infrastructure are of crucial importance in determining the vulnerability to climate change. A well connected population with appropriate public infrastructure will be able to deal with a

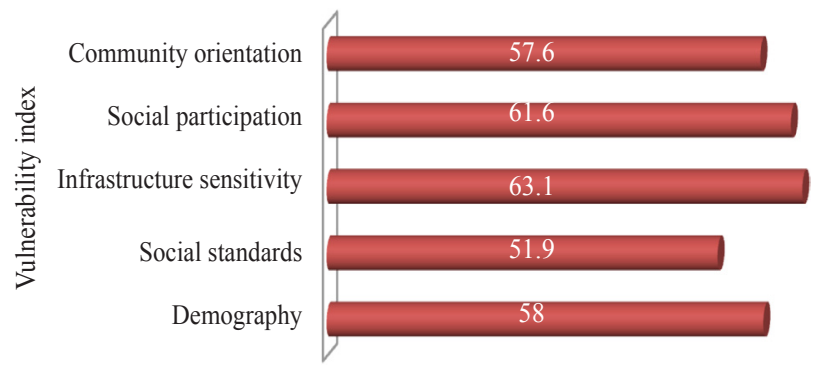

Fig. 6. Attribute analysis on social vulnerability; VI: Vulnerability Index

hazard, effectively and reduce the vulnerability (Handmer et al., 1999). Negligible training programmes, minimal sharing of technical knowledge and awareness as well as very low grass root planning were the causal factors for increased social vulnerability.

d) Attributes analysis of climate change impacts on economic aspects

Socio-economic variables are significant factors contributing to coastal vulnerability mainly because socio-economic changes occur more often and rapidly than physical process changes (Szlafsztien, 2005; Anirban et al., 2012). It is hence imperative to consider socio-economic variables along with environment and fishery attributes, as this would enhance the accuracy and clarity of results related to coastal vulnerability as the magnitude of a natural calamity is often described in terms of the devastation it causes to human, natural and anthropogenic resources (Mani Murali, 2013).

The perception on the economic drivers impacting climate change in the fishers' households was observed at low level. Cost of fishing is the highly impacted economic attribute followed by loss in fishing days and migration with income effect being the least impacted. It revealed that increased expenses by fuel, crafts and gear as well as changed fishing ground made the fisherfolk more vulnerable to climate related changes (Vincent and Cull, 2009) (Fig. 7). Fishers perceived the cost of fishing as very high and $25 \%$ ranked it as medium vulnerable attribute. Loss in fishing days due to erratic monsoon and sea erosion made fishers economically more vulnerable.

\section{Attributes analysis of climate change impacts on} environment

The vulnerability index by environmental attributes for Cuddalore District of Tamil Nadu is depicted in Fig. 8. Environmental attributes were the least impacted, among which sea level rise being the highly impacted attribute followed by extreme weather events and monsoonal fluctuation (Rao et al., 2008). Rising sea level greatly 


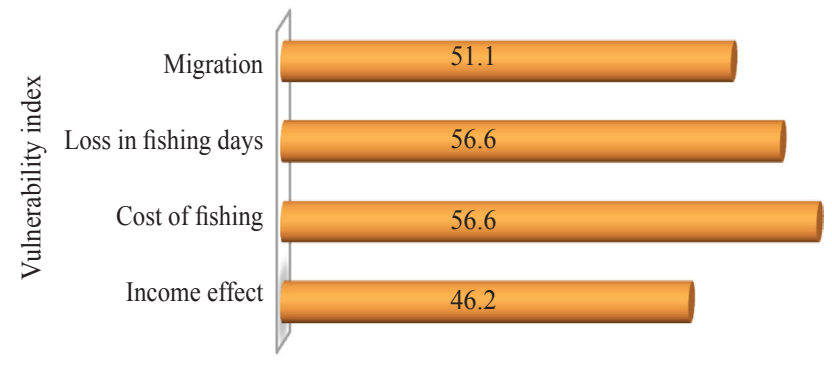

Fig. 7. Attribute analysis on economic vulnerability; VI: Vulnerability Index

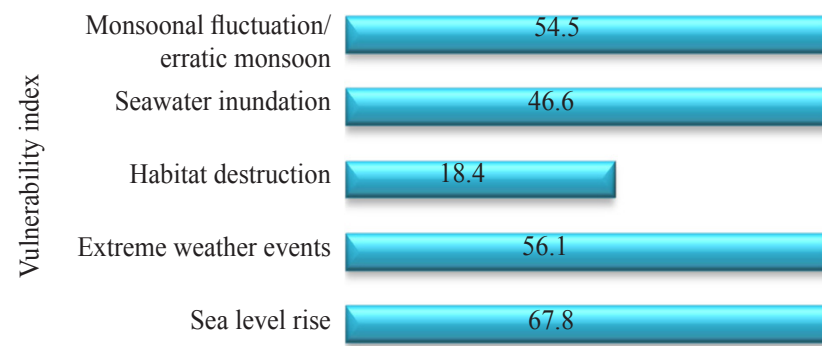

Fig. 8. Attribute analysis on environmental vulnerability; VI: Vulnerability Index

enhances the threat of flooding and salt water infusion. Hence any occurrence of extreme events is likely to be catastrophic in nature for the coastal people of Cuddalore. With respect to monsoonal fluctuations, the respondents perceived that there is substantial decrease in rainy days over the years and erratic monsoon was observed. Pye and Blott (2006) reported that accelerated sea level rise and possible increase in the intensity and frequency of cyclones related to increase in sea surface temperature (SST) to cause serious ramifications such as flooding, coastal erosion and shoreline retreat. Substantial increase in sea level and coastal erosion in recent years impacted fishing and allied activities of fishermen in the fishing villages of Cuddalore.

\section{Attributes of village vulnerability}

The extent of sea erosion and consequent loss of shallow fishing areas adjoining the coast (within a distance of $2 \mathrm{~km}$ ) is very high in these villages particularly Pettodai, where the fishermen do not have docking space for their country craft. Considerable rise in sea level, increase in flood, erosion and habitat shift and cyclone occurrence were ranked as very high vulnerability attributes by majority of the Pettodai households. In pettodai fishing village, fishers perceived more impact on environmental and social attributes followed by fishery impacts, whereas fishery and economic attributes were impacted next to development drivers in Reddiarpettai (Fig. 9). In Sothikuppam fishing village, climate change was mostly

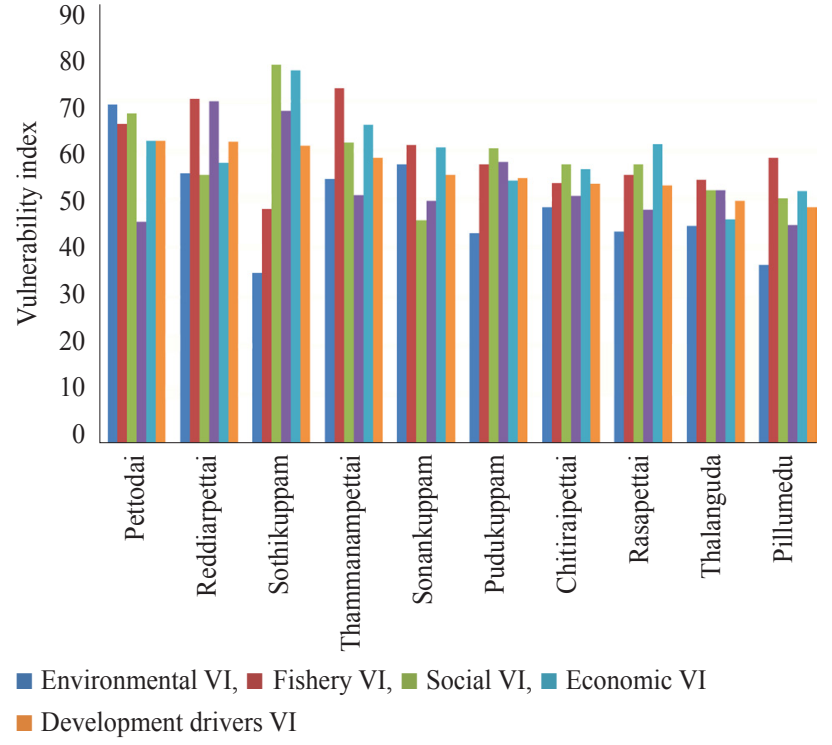

Fig. 9. Vulnerability assessment across coastal villages selected for the study; VI: Vulnerability Index

impacted by social factors based on fishers' perception on different attributes followed by development drivers and economic factors.

Pillumedu Village of Cuddalore District, situated in Pichavaram forest is comparatively less vulnerable when compared to other villages which showed possibilities of alternate avocations and was therefore selected as indicator village since it is rich in mangroves, marine and coastal biodiversity resources. Severe habitat destruction and seawater inundation during tsunami and Thane cyclone made Pettodai Village environmentally vulnerable to a higher extent (69.4). Thammanampettai Village showed very high fishery vulnerability index (72.8). Drastic change in species composition, catch and distribution of fish species in recent years was the reason for the intense vulnerability in this village. Fishers of this village perceived that vulnerability on fishery was very high in which catch (80.1) was the major attribute which reduced drastically in recent years.

Social and development drivers VI for Sothikuppam Village were 77.6 and 76.4 respectively which clearly indicated deficiency in education, health, sanitation facilities and the close proximity of this village to hazard zone. Fishers opined that lack of social participation (89.5) in terms of negligible training and awareness programs, less social participation among fishers, unshared technical knowledge among fishers and negligible community based grass root planning made the situation worst in addition to climate driven impacts. Rapid development of various industries and lack of communication facilities render Sothikuppam Village highly vulnerable to climate related changes. 
Creation of infrastructure drivers by way of commissioning power plants along coasts, unplanned transportation facilities, unregulated development of industries and increased illegal land conversions were the major development drivers perceived by respondents contributing towards higher vulnerability. Fishermen also ranked ICT enabled drivers (82.3) as the major subindicator next to lack of infrastructure drivers which led to high vulnerability by climatic factors. Economic VI was very high for Reddiarpettai Village (61.7) which might be due to increased expenses for fishing activities and climate related changes. Fishers opined that cost of fishing was the major reason for high economic vulnerability in this village and vulnerability index was 81.6. Cost of fishing has increased in recent days mainly in terms of increased fuel cost, crafts and gear modifications and changed fishing ground. Loss in fishing days (74.2) due to cyclones and storms which led to increased health hazards, economic loss and loss of income from alternate avocations was ranked as highly vulnerable by the respondents of this village.

Vulnerability due to natural disasters, the possibility of increase in number and enormity of such events under climate change regime and their potential high impact on the performance of climate sensitive sectors make a strong case for focus on adaptation and mitigation policies. In the light of the changing climate, computation of vulnerability index is necessary in order to take appropriate measures to protect the people and property. It is important to assess the fisherfolk vulnerability to climate change in planning, prioritising developing and implementing the right mix of adaptation and mitigation intervention in equipping the community. Thus, the development of coastal vulnerability indices to climate-related impacts is a basic prerequisite for obtaining an understanding of the risk of climate change to natural and socioeconomic coastal systems (Sterr, 2008).

The results of the present study clearly indicated that Cuddalore District is highly vulnerable. Fishers perceive that the fishery and development drivers attributes are of importance in the climate change adaptation and mitigation plans. The study has identified three villages, namely, Pettodai, Reddairpettai and Sothikuppam as highly vulnerable. The results confirmed the previous findings that the coastal stretches of Cuddalore District are in the high-vulnerable zones for climate related disasters. The respondents were very much prone to loss in fishing days and erratic monsoon in recent years. Fisher communities need to be involved in climate change adaptation and mitigation plans by improving their awareness on various aspects of climate change. The results of the study suggested that on the basis of ranking priorities of the vulnerability, the policy makers can implement suitable policies so as to reduce the risk of the selected coastal district and villages and to prevent loss of invaluable coastal land and displacement of people. This will be very much useful for planning suitable remedial measures to mitigate the adverse effects of climate change. However, it is important to involve the fishers in the proactive planning and implementation of such adaptation and mitigation options.

\section{Acknowledgements}

The authors are thankful to the Director, ICARCMFRI, Kochi for guidance, support and facilities. The study was conducted with financial support from Indian Council of Agricultural Research, New Delhi through the project National Innovations in Climate Resilient Agriculture (NICRA).

\section{References}

Ahamed Mansur 2013. Community based approach for reducing vulnerability to natural hazards (cyclone, storm surges) in coastal belt of Bangladesh. Procedia. Environ. Sci., 17: 361-371.

Allison, E. H., Perry, A. L., Badjeck, M. C., Adger, W. N., Brown, K., Conway, D., Halls, A. S., Pilling, G. M., Reynolds, J. D., Andrew, N. L. and Dulvy, N. K. 2009. Vulnerability of national economies to the impacts of climate change on fisheries. Fish Fish., 10: 173-196.

Anirban Mukhopadhyay, Rajarshi Dasgupta, Hazra, S. and Mitra, D. 2012. Coastal hazards and vulnerability: A review. Int. J. Geol., Earth Environ. Sci., 2(1): 57-69.

Bhattacharya Sumana and Aditi Das 2007. Vulnerability to drought, cyclones and floods in India. Basic Project funded by the European Commission, Winrock International, India. http://www.basicproject.net/

CMFRI 2006. Marine fisheries census 2005 Part III (4), Tamil Nadu. Department of Animal Husbandry, Dairying and Fisheries, Ministry of Agriculture, New Delhi and Central Marine Fisheries Research Institute, Kochi.

Dube, S. K., Rao, A. D., Sinha, P. C., Murty, T. S. and Bahulayan, N. 1997. Storm surge in the Bay of Bengal and Arabian Sea: the problem and its prediction. Mausam, 48: 283-304.

Dwarakish, G. S., Vinay, S. A., Natesan, U., Asano, T., Kakinuma, T., Venkataramana, K., Pai, B. J. and Babita, M. K. 2009. Coastal vulnerability assessment of the future sea level rise in Udupi coastal zone of Karnataka State, west coast of India. Ocean Coast, Manage., 52: 467-478. doi:10.1016/j. ocecoaman.2009.07.007.

Handmer, J. W., Dovers, S. and Downing, T. E. 1999. Societal vulnerability to climate change and variability. Mitigation and adaptation strategies for global change, 4: 267-281. 
IPCC 2007. Climate change, the physical science basis. In: Solomon, S., Qin, D., Manning, M., Chen, Z., Marquis, M., Averyt, K. B., Tignor, M. and Miller, H. L. (Eds.), Contribution of working group I to the fourth assessment report of the intergovernmental panel on climate change, Cambridge University Press, Cambridge, United Kingdom and New York, NY, USA, p. 996.

Jayakumar, S., Ilangovan, D., Naik, K. A., Gowthaman, R., Tirodkar, G., Naik, G. N., Ganesan, P., ManiMurali, R., Michael, G. S., Ramana, M. V. and Bhattacharya, G. C. 2005. Run-up and inundation limits along south-east coast of India during 26 December 2004 Indian Ocean tsunami. Curr. Sci., 88: 1741-1743.

Kasperson, J. X., Kasperson, R. E., Turner II, B. L., Schiller, A. and Hsieh, W. H. 2003. Vulnerability to global environmental change. In: Diekmann, A., Dietz, T., Jaeger, C. and Rosa, E. S. (Eds.), The human dimensions of global environmental change. MIT, Cambridge, MA, 100(14): 8074-8079.

Kumar, A. A. and Kunte, P. D. 2012. Coastal vulnerability assessment for Chennai, east coast of India using geospatial techniques. Nat. Hazards, 853-872. doi: 10.1007/s11069012-0276-4.

Kumar, T. S., Mahendra, R. S., Nayak, S., Radhakrishnan, K. and Sahu, K. C. 2010. Coastal vulnerability assessment for Orissa State, East Coast of India. J. Coast. Res., 263: 523-534. doi:10.2112/09-1186.1.

Mahendra, R. S., Mohanty, P. C., Bisoyi, H., Kumar, T. S. and Nayak, S. 2011. Assessment and management of coastal multi-hazard vulnerability along the CuddaloreVillupuram, east coast of India using geospatial techniques. Ocean Coast. Manage, 54: 302-311. doi:10.1016/j. ocecoaman.2010.12.008

Mani Murali, R., Shrivastava, D. and Vethamony, P. 2009. Monitoring shoreline environment of Paradip, east coast of India using remote sensing. Curr. Sci., 97: 79-84.

Mani Murali, Ankita1, R. M., Amrita, S. and Vethamony, P. 2013. Coastal vulnerability assessment of Puducherry coast, India using analytical hierarchical process. Nat. Hazards Earth Syst. Sci. Discuss, 1: 509-559.

Murthy. K. S. R., Subrahmanyam. A. S., Murty. G. P. S., Sarma. K. V. L. N. S., Subrahmanyam. V., Rao. K. M., Rani, P. S., Anuradha, A., Adilakshmi, B. and Sridevi, T. 2006. Factors guiding tsunami surge at the Nagapattinam-Cuddalore shelf, Tamil Nadu, east coast of India. Curr Sci., 90(11): $1535-1538$
Patnaik, U. and Narayanan, K. 2005. Vulnerability and climate change: An analysis of the eastern coastal districts of India, International Workshop on Human Security and Climate Change, 21-23 June 2005, Oslo, p.1-20.

Patwardhan, A., Narayanan, K., Parthasarathy, D. and Sharma, U. 2003. Assessment of vulnerability and adaptive capacity in coastal zones. In: Shukla, P. R., Sharma, S. K., Ravindranath, N. H., Garg. A. and Bhattacharya, S. (Eds.), Climate change and India: Vulnerability assessment and adaptation, Universities Press, Hyderabad, p. 326-359.

Pye, K. and Blott, S. J. 2006. Coastal processes and morphological change in the Dunwich-Sizewell area, Suol. UK, J. Coast. Res., 22: 453-473. doi: 10.2112/05-0603.1.

Ramanamurthy, M. V., Sundaramoorthy, S., Pari, Y., Ranga Rao, V., Mishra, P., Bhat, M., Usha, T., Venkatesan, R. and Subramanian, B. R. 2005. Inundation of seawater in Andaman and Nicobar Islands and parts of Tamil Nadu coast during 2004 Sumatra tsunami. Curr. Sci., 88(11) 1736-1740.

Rao Nageswara, K., Subraelu, P., Venkateswara Rao, T., Hema Malini, B., Ratheesh, R., Bhattacharya, S. and Rajawat, A. S. 2008. Sea-level rise and coastal vulnerability: an assessment of Andhra Pradesh coast, India through remote sensing and GIS. J. Coast Conserv., 12(15): 195-207. doi:10.1007/s11852-009-0042-2.

Sabarathnam, V. E. 1988. Manual on field experience training for ARS Scientists, National Academy for Agricultural Research Management, Indian Council of Agricultural Research, Hyderabad.

Saxena, S., Purvaja, R., Mary Divya Suganya, G. and Ramesh, R. 2012. Coastal hazard mapping in the Cuddalore region, South India. Nat. Hazards. DOI 10.1007/s11069-012-0362-7.

Small, C. and Nicholls, R. J. 2003. A global analysis of human settlement in coastal zones. J. Coastal Res., 19: 584-599.

Sterr, H. 2008. Assessment of vulnerability and adaptation to sea-level rise for the coastal zone of Germany. J. Coast Res., 242: 380-393.

Shyam S. Salim, Kripa, V., Zachariah, P. U., Anjana Mohan, Ambrose, T. V. and Manju Rani 2014. Vulnerability assessment of coastal fisher households in Kerala: A climate change perspective. Indian J. Fish., 61(4): 98-103.

Shyam S. Salim, Kripa, V., Zacharia, P. U., Shridhar, Nivedita and Ambrose, T. V. 2014. Climate change awareness, preparedness, adaptation and mitigation strategies: Fisherfolks perception in coastal Kerala J. Aquat. Biol. Fish., 2: 670-681. 
Szlafsztien, C. F. 2005. Climate change, sea-level rise and coastal natural hazard: a GIS-based vulnerability assessment, State of Par'a, Brazil. J. Coast. Conserv., 11: 53-66.

Vincent, Katharine and Cull, Tracy 2009. Climate change and food security mapping in the Southern African Development Community. Copenhagen: Danish Development Research
Network. http://www.ddrn.dk/filer/forum/File/DDRN SADC_Climate_Food_overview_rev_2010 (Accessed $9^{\text {th }}$ July 2013).

Vivekanandan, E. 2006. Impact of climate change on marine fisheries, CMFRI Newsletter, 112: 1-4. 